\title{
Prosperidade $x$ declínio: as representações da decadência em Minas Gerais na segunda metade do século XIX
}

\author{
Márcio Achtschin Santos
}

\author{
Palavras-chave: \\ Representações \\ Decadência \\ Segundo Reinado
}

Keywords:

Representations

Decay

Second Empire

\begin{abstract}
Resumo: A proposta deste artigo é analisar as representações construídas pela imprensa mineira sobre o espaço econômico e político ocupado por Minas Gerais no Império. Através do imaginário social, tendo como fontes os periódicos mineiros do Oitocentos, esse trabalho propõe repensar um antigo debate na historiografia mineira, qual seja: a decadência ou o crescimento de Minas no século XIX. Tendo como referência as representações construídas no discurso dos jornais, identifica-se, neste trabalho, um sentimento de declínio econômico e enfraquecimento político da província mineira a partir dos anos de 1840.
\end{abstract}

Abstract: The purpose of this article is to analyze the representations constructed by the mining press on economic and political space occupied by Minas Gerais in the Empire. Through the social imaginary, having as sources the eight mineiros periodicals, this work proposes rethinking an old debate in the mineiro historiography, namely: the decay or growth of Minas in the nineteenth century. With reference to the representations constructed in the discourse of newspapers, is identified, in this work, a sense of economic decline and political weakness of the mineira province from the 1840s.

Recebido em 19 de outubro de 2016. Aprovado em 30 de janeiro de 2017.

\section{Introdução}

Na década de 1980, a historiografia produziu revisões significativas com relação aos aspectos econômicos e sociais de Minas Gerais. O chamado modelo clássico explicativo, tendo como referência especialmente Roberto Simonsen (1977), Celso Furtado (2001) e Caio Prado Júnior (1972), apontava para uma região mineira estagnada no Oitocentos, em uma produção agropecuária de subsistência que não conseguia substituir a economia mineradora.

$\mathrm{Na}$ visão contemporânea, quebrou-se o velho modelo, reconhecendo que o crescimento da população do Oitocentos esteve vinculado a uma dinâmica de mercado em Minas Gerais, em uma economia que não estava fechada em si mesma. A análise da economia mineira do século XIX foi ampliada em estudos como o de Maria Yedda Linhares (1979), que não questiona o esgotamento da mineração, mas procura perceber o impacto da crise sobre as mais diversas formas de economia mineira que se articulavam no interior da província. Foram dadas novas perspectivas ao universo mineiro do Oitocentos, caso do estudo de Roberto Borges Martins (1980), Robert Slenes (1988), Douglas Cole Libby (1988), dentre outros.

Caminhando ao encontro desse contexto econômico na província mineira, Alcir Lenharo (1979) aponta para o importante papel de Minas Gerais na transição da colônia para o Império, inserindo o núcleo produtor e abastecedor mineiro na formação do Estado nacional. Com a presença da Corte portuguesa no Brasil a partir de 1808, houve um fortalecimento da economia mineira, que passou a abastecer de gêneros de subsistência o Rio de Janeiro e outras províncias próximas. Minas Gerais viveu nesse período uma diversificação produtiva sem precedentes. Para Lenharo (1979), esse setor é somente uma fatia do mercado da Corte, mas a mais rica, inclusive se comparado ao setor exportador. Assim, o comerciante mineiro abastecedor do mercado carioca assumiu de forma crescente 
um importante papel político, especialmente durante a regência com uma tendência chamada genericamente de liberais moderados. Fazendo referência aos comerciantes mineiros, Alexandre Mendes Cunha (2013) reforça a perspectiva de Lenharo, afirmando que: "Na arena política, os tropeiros conquistam cargos de deputado e senador, levando sua agenda para o centro das discussões governamentais e impulsionando de vez as relações econômicas entre o sudeste" (CUNHA, 2013).

A partir dessas obras, desdobraram-se estudos que consolidaram e consagraram a ideia de uma Minas Gerais no século XIX que se desenvolveu e superou a crise mineradora por meio de grande diversidade econômica. A condição de mais populosa província do Brasil, principal abastecedora da Corte, além da proximidade geográfica com o Rio de Janeiro, fez com que Minas Gerais assumisse um importante papel na construção do Estado nacional. Ainda assim, é difícil precisar o que foi realmente a economia de Minas Gerais ao longo de todo o período imperial. Conforme sugere Afonso Alencastro Graça Filho (2002), uma pesquisa sólida sobre a economia de Minas Gerais, pela própria diversidade e pelas mudanças ocorridas ao longo de todo o século XIX ainda está pendente.

Desse modo, o aspecto central levantado nesse artigo é o debate em torno do papel político e econômico de Minas Gerais, especialmente após a consolidação do café como principal produto exportador. E essa questão é pensada através das representações produzidas pela imprensa mineira no império, tendo como referência o clássico debate na historiografia sobre a crise e/ou crescimento econômico de Minas Gerais no século XIX. Logo, o objetivo é utilizar categorias que tenham uma abordagem não apenas quantitativas para economia ou apenas racionais para o universo social e política; afinal, no jogo do poder também estão presentes sentimentos, valores, emoções e as fontes históricas possibilitam um farto material no qual estão presentes representações que não podem ser ignoradas e incluem: "Ideologia, linguagem, memória, imaginário e iconografia, e mobilizam, portanto, mitos, símbolos, discursos, vocabulários [...]" (MOTTA, 2009, p. 21).
Com isso são adotadas categorias como o imaginário e os mitos para analisar a política, propondo a cultura também como ferramenta de análise da história. Conforme afirmar Raoul Girardet (1987), não existe um código imaginário a partir de exclusivas abstrações, que nascem de uma situação vivida e, como consequência, existe uma receptividade de seus agentes. Para o autor, essa construção não partiu de uma explicação meramente ilusória ou manipuladora, visto que nasceu de uma percepção da realidade. Assim, as representações surgem de uma realidade específica ao mesmo tempo em que criam essa realidade. Ele recusa as imagens construídas somente: "[...] no exclusivo plano da fábula, em um universo de pura gratuidade, de transparente abstração, livre de todo contato com a presença das realidades da história" (GIRADET, 1987, p. 51).

Ou seja, se há demonstrações suficientes para constatar que houve um crescimento em Minas Gerais nas primeiras décadas, é possível pensar nessa continuidade também na segunda metade do Dezenove? De que modo as representações produzidas pela imprensa mineira podem contribuir para propor uma análise de uma possível decadência da economia na província ao longo do Império?

Tendo como fontes os periódicos mineiros entre 1825 e 1889 disponíveis $^{1}$, este artigo foi dividido em dois subcapítulos. Em um primeiro momento, procura-se perceber como os mineiros, a partir dos periódicos, incluem-se no Império tendo como referência especialmente as outras províncias. $\mathrm{Na}$ segunda parte, ainda tendo como referência os jornais da província, a proposta deste estudo é identificar como o mineiro constrói sua imagem diante da própria realidade vivida no Segundo Reinado. Por fim, esse segundo capítulo se subdivide em sentimento de decadência e suas representações construídas a partir desse cenário.

\section{Minas olhando para fora}

Dos diversos temas tratados pela imprensa mineira no século XIX, um dos mais constantes foi a situação econômica e política da província durante o império. Essas produções alternaram ao 
longo desse período. Entre os anos 1820 e 1840, era descrita pela imprensa provincial como uma região desenvolvida, principal abastecedora da Corte e proximidades, exercendo forte influência nas decisões políticas nacionais. Os periódicos apontavam para uma Minas Gerais próspera, muito próxima aos interesses do recém-criado Estado brasileiro, pactuando e tendo benefícios com a aliança entre império e província.

A referência ao território era sempre vista com orgulho e uma forma de destacar sua grandiosidade. O jornal “O Universal” faz constantes referências ainda no governo pedrino, apontando Minas como a "maior província do império"2 ou, dois anos depois, aumentando a extensão territorial ufana sobre Minas Gerais: "A província de Minas, que faz a quarta parte do Império"3. Mas o orgulho do papel mineiro no cenário nacional não se limitava à sua vastidão territorial, e era exposto reiteradas vezes: "Minas, esta província que tanto pesa na balança política do Estado por sua população, e riqueza vai dar agora um grande impulso à marcha de nossa civilização" ${ }^{4}$ ou "é maior, a mais vasta, a mais rica, a mais populosa de todo o Império"s.

E, por ser significativo para a economia, consequentemente, tinha importância para sustentar os gastos públicos com sua arrecadação, sendo "a que mais concorre indiretamente para

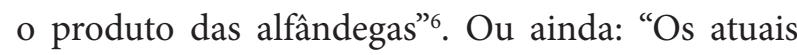
impostos não devem fazer peso a uma província tão rica e populosa como a de Minas" ${ }^{\prime \prime}$. Ocorrem publicações nesse sentido no Primeiro Reinado. E, no período regencial, o sentimento é de prosperidade. É emblemática a opinião de um leitor assinado por "um patriota não suspeito", de Mariana, sobre Minas Gerais: "A verdade incontestável e geralmente reconhecida é que nossa província de Minas vai bem, muito bem, oxalá ela se conserve sempre com tão bons auspícios".

Mas, na segunda metade da década de 1940 do Dezenove, há a sinalização de um sentimento que vai ser crescente no discurso por parte da imprensa mineira: as dificuldades econômicas da província em relação às outras províncias, especialmente Rio de Janeiro e São Paulo. Ainda que não tivesse perdido a importância no cenário nacional, Minas Gerais aparentemente deixou de ter o poder econômico e político que tinha nas primeiras décadas de Império. O que os periódicos mineiros indicam a partir de meados nos anos 1940 em diante é que seu poder decisório passou a ter menor peso do que os anos 1920 e 1930.

Essa percepção que a imprensa tinha com relação à perda de espaço no cenário nacional se fazia presente ao longo de toda a metade do século XIX, como pode ser visto no discurso do deputado provincial Salathiel Andrade Braga: Minas Gerais, a mais rica e grandiosa das primeiras décadas de 1920, agora é a "talvez mais rica do império, mas não ostenta suas grandezas"’. Já é perceptível o sentimento de perdas para as outras duas concorrentes províncias do sudeste: A decadência de nossas minas e as despesas de transportes arredaram da província grandes capitais que foram arrotear as matas virgens do Rio de Janeiro e São Paulo e transportar para ali a riqueza e civilização mineira, a mais antiga do sul do Brasil ${ }^{10}$.

Ademais, a constatação dos problemas vividos em Minas Gerais foi narrada em artigo assinado por José Jorge da Silva, que afirma que pouca gente migrava para Minas, mas que muitos saiam tendo como razões as perseguições políticas e que "[...] a esperança de maiores lucros tem sustentado uma corrente de emigração mineira para São Paulo, Rio de janeiro e Goiás" ${ }^{11}$. Foi frequente na imprensa a confirmação da redução populacional em Minas Gerais na segunda metade do século XIX. Ainda que não precisos, são dados que podem oferecer uma situação de dificuldades econômicas se comparados com os das outras províncias. O "Correio Oficial de Minas"12 indicou uma população de 1 milhão de pessoas no ano de 1821 e, em 1859, 1 milhão e 300 mil. Porém, para o periódico, deveria ser o dobro, mas 500 mil migraram para fora da província.

Joaquim Caetano da Silva Guimarães, em um longo estudo publicado no jornal "Correio Oficial de Minas" ${ }^{\prime 13}$, em 1859, considerava que, com a exploração predatória em Minas Gerais, ocorreu a dispersão da população, calculada em $500 \mathrm{mil}$ mineiros saídos da província. Guimarães menciona que a população, que era em 1821 de um milhão chegou ao final dos anos 1950 a 1 milhão e 300 mil, 
sendo que deveria, segundo o autor, ter dobrado. O periódico "O Conservador de Minas"14, em 1870 comentava que ocorreu a saída de mineiros para o Rio de Janeiro, Espírito Santo e São Paulo em busca de terras produtivas, estas já esgotadas em Minas Gerais.

O sentimento de não ser mais a primeira transpareceu no "Correio Oficial de Minas", ao indicar na província "um atraso igual somente a três províncias"15 ou no mesmo jornal do ano seguinte, quando Minas passou a ser a "oitava receita geral do Estado" ${ }^{16}$. Não se tratava de ser situação ou oposição ao governo, já que cada um a seu modo demonstrava pela imprensa a perda de espaço da província ao longo de toda metade do Dezenove.

No início dos anos 1960, já com a política de Conciliação perdendo fôlego, os lamentos saudosos crescendo pelo "indiferentismo, esse estado sempre condenável, principalmente quando se trata da causa pública [...] sono tão fatal ao país"17, as eleições para deputado provincial traziam à tona a comparação com as outras províncias. Assinado por um leitor que se denomina "O Progressista", um artigo denunciava a apatia política dos últimos anos que impactou a província, entendendo que Minas Gerais "[...] viu ir-lhe escapando insensivelmente sua preponderância, viu suas irmãs adiantaremse e irem a deixando na retaguarda [...] nenhuma província tanto sofreu, nenhuma retrogradou tanto"18. Para os que contestavam a política Conciliatória, que sentiram nos liberais mais extremados o recuo "[...] uns votados ao ostracismo, outros ceifados pela morte, outros finalmente retiraram às suas tendas julgando ter cumprido sua missão"19. E o retorno das velhas tradições e lutas serviriapara que Minas readquirisse "o prestígio e a influência de que já gozou"20. No discurso político fundado na esperança de dias melhores, havia a evidência de que Minas Gerais não ocupava mais o centro das atenções políticas: "dentro em pouco ela pode reconquistar a posição perdida" ${ }^{21}$.

Também havia um lamento constante da imprensa mineira quanto ao tratamento desigual dado à província em comparação com as outras: "reclamai porque a província de Minas também faz parte do império, também tem direito a um quinhão na partilha de benefícios e de favores que se fazem às suas irmãs"22. O tom pouco otimista quando se refere aos mineiros também povoou o discurso dos conservadores, na condição de opositores em 1866. O porta-voz é o periódico "Constitucional", de propriedade dos bacharéis Camilo da Cunha e Figueiredo e Benjamin Rodrigues Pereira, e apontava no passado mineiro para a supremacia quanto às demais províncias: "Era a mais influente e enérgica de suas irmãs"23.

Nos anos 1970, a imprensa já se apresentava abatida diante da impossibilidade de se igualar ao avanço das outras províncias. Ao comentar sobre a política nas províncias, o jornal sul mineiro "Colombo" buscou o exemplo: "nas três províncias mais adiantadas - São Paulo, Bahia e Rio Grande"24. Também em editorial, o "Diário de Minas" ${ }^{25}$, de 10 de março de 1877, lamentava que, apesar do território e da herança deixada nas tradições, já não desejava ser a primeira, só não queria estar como última.

Aproximadamente dez anos depois, esse sentimento pouco mudou. O "Minas Altiva" em dois momentos destacava a falta de prestígio e o atraso da província mineira: "A nossa querida província passa por uma crise medonha. Enxotaram-na para fora da nação. Enxotam-na para fora da nação. Não tem dinheiro, não tem apoio, não tem autonomia"26 ou: "O progresso de Minas tem a mesma marcha de um caranguejo [...]"27. Às vésperas da república, ainda era o atraso a marca mineira se comparada com outras províncias: "Por que, em tantas riquezas, no meio de tantas virtudes, a condição do mineiro é precária, é ruim, é inferior à de alguns habitantes deste próprio país"28.

A província que ostentava seu papel fundamental na economia nacional, abastecedora da capital do Império no princípio do século XIX, tinha sua posição invertida. O lamento fazia referência à dependência de produtos vindos do Rio de Janeiro: "É por tais motivos que a província não tem ainda plano definitivo para sua viação férrea; que não tem ainda estabelecimentos fabris que a isentem de comprar tudo no Rio de Janeiro, é por isso que sua instrução jaz até hoje no período rudimentário $[s i c]^{29}$. 
Havia, na permanente comparação entre o desenvolvimento econômico de Minas Gerais e outras províncias, a evidência do sentimento marcado pelas perdas. A província paulista se tornou o símbolo do progresso e desenvolvimento: "São Paulo, que é hoje o que Minas outrora foi" Ou: "São Paulo avança a passos de gigante e nós não podemos continuar a dormir o sono da desgraça, confinado com a nossa próspera irmã, envergonhando-nos da nossa inércia monstruosa"31. Para os periódicos, até a forma de fazer oposição em São Paulo contribuiu para seu crescimento, pois, enquanto na província mineira havia no legislativo o veto de todas as obras, na província paulista, apesar de haver divergências entre partidos, existia a aceitação das obras da administração:

Trata-se de fazer uma estrada no norte, os despeitados, as inteligências acanhadas e mesquinhas gritam que é desperdício, um escândalo. Trata-se de construir uma estrada no sul, gritase que esta parte da província tem as melhores estradas do mundo. E desta sorte nada se faz. O norte e o sul ficam sem estradas. A província continua o seu regresso, e toma-se a rabadilha de suas irmãs ${ }^{32}$.

Tudo na imprensa de Minas Gerais a partir da segunda metade do século XIX representava retrocesso, quer seja na economia, quer seja na política, quer seja na população, especialmente se comparada com Rio de Janeiro e São Paulo. Um discurso que incomodava até mesmo as da época. O lamento do jornal liberal de 1878 denuncia essa frequência: "[...] parece obra encomendada a gente de fora da terra. Fala muito em Minas e mineiros, que andam atrasados, etc., etc., etc." ${ }^{33}$.

\section{Minas olhando para si}

Esse discurso não brotou apenas da capital e das proximidades. Esteve presente no sul, na região do triângulo mineiro e no norte de Minas Gerais. A documentação existente não deixava dúvidas para exceções, não só pelas correspondências e pelos artigos recebidos pela imprensa na capital mineira vindos do interior como também pelos diversos jornais disponíveis de todas as regiões da província. Foi um lamento comum e em nenhum momento ocorreu uma advertência para exceções em situações que não acompanhassem em Minas Gerais esse sentimento de decadência.

Do mesmo modo que a imprensa mineira percebia a província em descompasso com as outras, um olhar para si conduzia a novas formas de identificação regional. Talvez pela dificuldade de construção de representações em maiores extensões territoriais, as primeiras narrativas eram localizadas, percebidas em vilas e cidades, não incorporando a província dentro desse sentimento de ruína. Uma série de artigos assinados com o codinome "O Abelhudo", publicados no jornal "O Bom Senso" em 1855, fazia uma descrição de diversas regiões mineiras, pintando um quadro desolador dos lugares por onde passou o escritor que se dizia viajante. $\mathrm{O}$ autor dessa série de textos sobre a região mineira fez uma narrativa da ruína de duas localidades, Araxá e Itatiaiuçu. Da primeira, descreveu que:

É a mais antiga vila e foi a mais opulenta destes lados da província. Hoje decaída e ameaçada de completa ruína, recorda com saudades dos belos tempos de seu esplendor. Foi a Silvaris [sic] ou Capua [sic] do sertão; o luxo e a moleza, aí reinavam, os prazeres sensuais tinham um culto extraordinário ${ }^{34}$.

Sobre Itatiauçu, região próxima à Santa Luzia, descrevia que, opondo-se o passado de prosperidade, ao redor da Igreja Matriz:

Circundam as mesmas sofríveis mas desprezadas casas, dentre estas uma meia dúzia de sobrados, ainda que de má arquitetura. [...] tudo, porém, em tal estado de ruína que contresta [sic] uma alma pensadora, e se umas são habitadas, o que se descobre por uma cabeça que a medo lá aparecem na janela, outras existem inteiramente fechadas, enquanto algumas servem de habitação de animais ${ }^{35}$.

Ainda em 1855, em um espaço para publicações literárias chamado "Folhetim do Bom 
Senso", um conto intitulado "Itinerário da saudade ou visita às ruínas do Caraça", citava o caso de um médico, nascido no arraial de Antônio Pereira, que retornou ao local para rever onde passou sua infância, e que, para sua surpresa, encontrou o lugar em ruínas:

O doutor aproximou-se do lugar em que nascera e, vendo somente com vida uma limeira, agarra-se a esta como uma pessoa que alguma coisa pudesse dizer sobre o fim que tinham tido os habitantes daquela casa ou onde estavam os primeiros e belos tempos de sua vida ${ }^{36}$.

Quatro anos depois, em um artigo assinado por "um viajante", a descrição feita do município de Caeté também era de desolação: o mais antigo de Minas, e que mais floresceu, hoje se vê reduzido à completa decadência e quase aniquilado; o comércio que em atividade o colocava na ordem dos mais importantes municípios da província, hoje quase extinto e pouco animador ${ }^{37}$

No entanto, gradualmente o que era descrito em Araxá, Itatiaiuçu, Antônio Pereira, Caeté já se torna um sentimento de toda a província. Do final dos anos 1950 em diante, a decadência passou a ser percebida não como fato isolado regionalmente, pertencendo apenas a localidades específicas, mas como um aspecto mineiro, na província como um todo. Em 1857, havia um sentimento, se não de estagnação, de um lento desenvolvimento era narrado no periódico "Correio Oficial de Minas". Ao propor em artigo a criação de uma associação industrial, o autor anônimo afirma que Minas Gerais se encontrava "[...] num estado aquém daquele que talvez poderíamos ter chegado. A mais tem-se conservado quase estacionário ou em progresso lento"38.

Fazendo uma longa análise, a qual foi publicada no "Correio Oficial de Minas"39 em 1859, Joaquim Caetano da Silva Guimarães apontava como causa da decadência mineira a exploração agrícola e pecuária predatória. Escrevendo de Formiga, região do Centro-Oeste mineiro, ao buscar uma explicação para a condição em que se encontrava a província, transmite um sentimento de declínio que se estendia a Minas Gerais como um todo, já não mais percebido apenas em localidades específicas.

Além do sul de Minas Gerais, gradualmente, relatórios da situação vivida em determinadas regiões vão se tornando mais amplos, assumindo uma perspectiva provincial. Continuavam as críticas locais, como a correspondência vinda de Mar de Espanha que assim descreve a cidade: "Este lugar parece que pisou Pilatos, pois que as duas únicas corporações que há são as ilustríssimas Câmara Municipal e Irmandade de Nossa Senhora das Mercês; porém, todas as duas em estado digno de compaixão" ${ }^{\prime 0}$.

Esse diagnóstico das situações vividas pela província de Minas Gerais era mais bem percebido se comparado ao passado, denunciando o fim do vigor e das influências econômicas e políticas que tinham os mineiros até o período regencial. Permaneceu essa imagem com um sentimento saudosista, construção de um local que já foi a região mais importante do Brasil, mas que perdeu sua posição a partir do Segundo Reinado.

\section{Decadência e retorno ao passado}

Dos anos de 1860 em diante, emergiu um discurso de uma província decadente em contraposição a um passado glorioso. O tempo de antes, o passado de desenvolvimento e prosperidade tanto representou uma projeção de um período aurífero que, segundo o imaginário, era um tempo de luxo e riqueza, bem como havia um sentimento em Minas Gerais de uma província desenvolvida economicamente e de grande importância também na vida política nacional até a década de 1930 do século XIX. E, diante do sentimento de decadência vivido em Minas Gerais, que a busca ao passado incorporou o imaginário mineiro.

Há, portanto, a lógica do discurso mitológico para interpretação das desordens do presente, expressando no tempo vivido pelos atores a imagem de nobreza de um passado mítico. O discurso apropriava-se do passado para o reencontro com a identidade coletiva perdida, funcionando como explicação dos acontecimentos bem como 
apresentando respostas para o futuro, ainda que dentro da coerência mítica. A decadência não era apenas entendida dentro do quadro meramente econômico, conforme artigo assinado por Virginis, em 1860, ao criticar a prática do deslocamento do braço operário para guarda nacional: "A gangrena moral é palpável, visível e medonha" ${ }^{\text {"41 }}$, e reforçava seu argumento citando Martinho Campos no mesmo periódico: "É na verdade a formosa província de Minas, o berço da liberdade, a pátria dos nossos primeiros mártires, a estrela brilhante do sul, hoje partida e desmatada oculta o rosto por entre as nuvens".

A decadência sentida por diversos setores vai assumir, a partir dos anos 1960, sua função explicativa para o proveito dos mais variados grupos sociais. Já estava presente, em artigo da primeira edição do "Constitucional" dos conservadores, ao responsabilizar a ruína agrícola, comercial e moral de Minas Gerais aos governantes progressistas e para tanto utilizava como argumento para reforçar a imagem de decadência todo o passado de glórias, em lutas sempre vencidas pelos locais:

Era a mais influente e enérgica de suas irmãs: reduziu o estado de decadência o fatal domínio progressista que sob ela pesa como um jugo de ferro. Em 1708 resistiu com denoso [sic] às tropas do Rio, fazendo-as retroceder caminho, em 1720 , com as armas e o punho intrépida constrangeu o governo revogou as leis dos quintos, em 1842 exibiu as mais significativas provas de adesão à causa pública. Atualmente nem o entusiasmo a anima. Tempo virá em que rebrecandolhe $[s i c]$ n'alma a flor dos sentimentos nobres que a ingratidão cresceu se faça Minas respeitar como em 1822 e $1831^{42}$.

Ligar o passado mineiro ao momento vivido pelos atores sociais dos anos 1960 foi uma ferramenta constante para criticar o governo dos progressistas, tendo como referência o passado de glórias da província. No intitulado "Comunicado aos Mineiros", enfatizavam-se as perdas sentidas pela província como também mais eram evidenciadas as riquezas do "tempo de antes":

Mineiros! Estais decaídos. Mineiros! O vosso estado mórbido já não se pode ocultar. A história de vossos antepassados, esses bravos, que arrostaram os cadafalsos, no século passado, as balas em 1833, e o canhão em 1842, é uma recordação gloriosa que não pode deixar de despertar a vossa coragem. Aí vai a história de vossas desgraças, sem exageração, sem romantismo nem poesia. A verdade não deve vestir as roupagens da mentira. Escutai $^{43}$.

No entanto, o declínio narrado pelos conservadores quando faziam oposição foi mantido quando voltaram ao poder. Apesar de toda a suntuosidade e todo o luxo das riquezas auríferas pertencerem ao imaginário, a decadência incorporava nesse período também a agricultura, que já não era suficiente para atender aos anseios da elite mineira como foi até os anos 1940. E a crise mineradora e a crise na economia agrícolacomercial em Minas Gerais se confundiam naquele momento, carregando a atemporalidade típica das construções míticas. O imaginado passado suntuoso do século XVIII se confundia com a prosperidade das primeiras décadas do século XIX.

Se havia a constatação pelos conservadores sobre a condição mineira, o partido liberal, antes opositor no governo, não alterava o discurso. $\mathrm{O}$ abatimento e a decadência persistiam como elemento definidor das condições mineiras e a esperança do reerguimento com a posse do Luzia Francisco P. Silveira Lobo na presidência da província era exposta em publicação assinada pelos diretórios liberais de Piumhy, Conceição e Januária:

A província de Minas, exm. Sr., em outras eras tão cheia de fulgos e brilho, tão florescente tão próspera, tão pujante de seiva e de vida, acha-se, no entanto, desde alguns anos a esta parte um estado de completo e progressivo declínio..Para erguê-la, pois desse estado de prostração e abatimento em que ora se acha e do qual com razão se sente envergonhada e humilhada.. mister se tornava que à frente de sua administração fosse colocado um cidadão dotado de grande energia e vontade ${ }^{44}$.

Por sua vez, estando agora na oposição, os conservadores do jornal "Província de Minas", 
ao criticar em editorial o governo liberal, somente corroboravam com a percepção de uma Minas Gerais em decadência, em nada indicando que estaria vivendo uma crise passageira, pois o discurso era contínuo: "Esta grande província já teve dias de prosperidade e de glória. Sua recordação deve estimular os tíbios a guiar os resolutos. Cumpre que nos esforcemos todos por melhorar a situação infeliz desse povo, generoso e bom" ${ }^{45}$.

\section{Conclusão}

Através da imprensa provincial, o que se pode perceber foi que, até a metade do século XIX, a elite mineira foi um importante centro abastecedor da região Centro-sul brasileira. Ao mesmo tempo, tinha significativa representatividade política, estando bem próxima ao poder central. Os temas comuns ao projeto da Corte se confundiam e reforçavam os laços entre Minas Gerais e o Império.

A partir do Segundo Reinado, gradualmente a região mineira vai incorporar ao seu discurso um sentimento de decadência, sinalizando perdas de espaço econômico e político. Esse sentimento de decadência pode ser percebido de forma contínua e permanente ao longo de toda a segunda metade do século XIX imperial nas diversas produções publicadas nos periódicos das mais variadas tendências e regiões, tornando-se um lamento contínuo.

Há indícios de que Minas Gerais não acompanhou as mudanças como outras províncias. Sua inserção não trouxe o mesmo avanço que se verificou no Rio de Janeiro e em São Paulo, que justificaria a proximidade constante do discurso na imprensa mineira em busca da modernidade. Ainda que se pudesse contra-argumentar que é uma construção no campo das representações, não se tem na imprensa mineira uma imagem com tanta permanência, vinda de diferentes regiões e diversos atores, como o discurso em torno da decadência na região. É muito pouco provável que uma abordagem ininterrupta como a derrocada da província mineira, permanentemente tratada pela imprensa provincial a partir dos anos de 1840, tenha apenas pertencido ao imaginário. Não é possível manter uma narrativa de maneira tão contínua simplesmente no campo da imaginação, exclusivamente na abstração de um pensamento sem qualquer vínculo com uma realidade histórica.

Minas Gerais esteve no centro decisório da política brasileira até os anos de 1830 . Portanto, se a província era visível e procurou, nos anos de 1850, ser novamente percebida, ser "re-vista", pode-se pensar na possibilidade de que teve dividido com outras províncias seu espaço na política imperial. Se ainda existe uma dificuldade no campo da história econômica em se diagnosticar essa situação, no campo das representações esse sentimento de decadência se encontra continuamente expresso pela imprensa mineira a partir da segunda metade do século XIX. Esse aspecto sugere uma relativização do permanente discurso de uma economia mineira em crescimento após a mineração ou pelo menos procura estabelecer um limite temporal para esse crescimento. Com isso, é pertinente propor para a historiografia econômica estudos que relacionem essas representações da imprensa mineira com indicadores não apenas quantitativos.

\section{Notas}

1 Os periódicos citados neste estudo foram consultados no Arquivo Público Mineiro (APM).

2 O Universal, $\mathrm{n}^{\circ} 01,18 / 07 / 1825$ (APM).

3 O Universal, $n^{\circ}$ 599, 27/05/1831 (APM).

4 Astro de Minas, $n^{\circ} 856,11 / 05 / 1833$ (APM).

5 O Universal, $n^{\circ}$ 924, 04/09/1833 (APM).

60 Universal, $n^{\circ}$ 987, 03/02/1834 (APM).

7 O Universal, $\mathrm{n}^{\circ} 11,27 / 02 / 1837$ (APM).

80 Universal, $n^{\circ} 679,30 / 11 / 1831$ (APM).

9 O bom senso, $n^{\circ}$ 42, 07/07/1852(APM).

10 O Bom senso, $n^{\circ} 146,19 / 07 / 1853$ (APM).

11 O Bom Senso, $n^{\circ} 235$, 12/06/1854 (APM).

12 Correio Oficial de Minas, $\mathrm{n}^{\circ} 282,19 / 09 / 1859$ (APM).

13 Correio Oficial de Minas, $n^{\circ} 282,19 / 09 / 1859$ (APM).

$14 \mathrm{O}$ conservador de Minas, $\mathrm{n}^{\circ} 07,12 / 03 / 1870$ (APM).

15 Correio Oficial de Minas, $\mathrm{n}^{\circ} 76,12 / 10 / 1857$ (APM).

16 Correio Oficial de Minas, $\mathrm{n}^{\circ} 103,14 / 01 / 1858$ (APM).

17 O Bem Público, n 47, 17/12/1860 (APM). 
18 O Bem Público, $n^{\circ} 47,17 / 12 / 1860(A P M)$.

19 O Bem Público, nº 47, 17/12/1860 (APM).

20 O Bem Público, ${ }^{\circ}$ 47, 17/12/1860 (APM).

21 O Bem Público, n 47, 17/12/1860 (APM).

22 Correio Oficial de Minas, $\mathrm{n}^{\circ} 245,12 / 05 / 1859$ (APM).

23 Constitucional, $\mathrm{n}^{\circ} 1,18 / 08 / 1866$ (APM).

24 Colombo, $n^{\circ} 154,26 / 01 / 1879$ (APM).

25 Diário de Minas, $\mathrm{n}^{\circ}$ 792, 10/03/1877 (APM).

26 Minas Altiva, ${ }^{\circ}$ 02, 02/04/1886 (APM).

27 Minas Altiva, S/E, 07/09/1886 (APM).

28 A Pátria Mineira, $n^{\circ} 11,25 / 07 / 1889$ (APM).

29 A Pátria Mineira, $n^{\circ}$ 04, 06/06/1889 (APM).

30 Colombo, $n^{\circ} 136,22 / 09 / 1878$ (APM).

31 A União, $n^{\circ} 82,22 / 06 / 1887$ (APM).

32 Noticiador de Minas, $n^{\circ}$ 277, 15/02/1871 (APM).

33 A Atualidade, $n^{\circ} 43,04 / 07 / 1860$ (APM).

34 O Bom Senso, $n^{\circ} 350,01 / 10 / 1855$ (APM).

35 O Bom Senso, n 352, 08/10/1855 (APM).

36 O Bom Senso, n 353, 11/10/1855 (APM).

37 Correio Oficial de Minas, $\mathrm{n}^{\circ} 273,18 / 08 / 1859$ (APM).

38 Correio Oficial de Minas, $\mathrm{n}^{\circ} 76,12 / 10 / 1857$ (APM).

39 Correio Oficial de Minas, $\mathrm{n}^{\circ} 282,19 / 09 / 1859$ (APM).

40 Diário de Minas, $n^{\circ}$ 56, 15/08/1866 (APM).

41 Diário de Minas, $n^{\circ} 29,04 / 07 / 1866$ (APM).

42 Constitucional, $n^{\circ} 01,18 / 08 / 1866$ (APM).

43 Constitucional, $n^{\circ} 61,06 / 01 / 1867$ (APM).

44 Constitucional, $n^{\circ} 62,02 / 11 / 1867$ (APM).

45 A Província de Minas, $n^{\circ}$ 01, 10/07/1880 (APM).

\section{Referências}

CUNHA, A. M. Tropeiros em Alta. Revista de História. Disponível em: <http://www. revistadehistoria.com.br/secao/capa/tropeiros-emalta>. Acesso em: 8 ago. 2013.

FURTADO, C. Formação econômica do Brasil. São Paulo: Globo, 2001.
GIRARDET, R. Mitos e mitologias políticas. São Paulo: Companhia das Letras, 1987.

GRAÇA FILHO, A. A. A princesa do oeste e o mito da decadência de Minas Gerais: São João del Rei (1831-1888). São Paulo: Annablume, 2002.

LENHARO, A. As tropas da moderação: o abastecimento da Corte na formação política do Brasil, 1808-1842. São Paulo: Símbolo, 1979.

LIBBY, D. C. Transformação e trabalho em uma economia escravista: Minas Gerais no século XIX. São Paulo: Brasiliense, 1988.

LINHARES, M. Y. L. O Brasil no século XVIII e a idade do ouro: a propósito da problemática da decadência. In: Seminário sobre a cultura mineira no período colonial, 8., 1979, Belo Horizonte. Anais... Belo Horizonte: Conselho Estadual de cultura de Minas Gerais, 1979. p.?

MARTINS, R. A economia escravista de Minas Gerais no século XIX. Belo Horizonte: CEDEPLAR/ FALE/UFMG, 1980.

MOTTA, R. P. S. M. Desafios e possibilidades na apropriação de cultura política pela historiografia. In: __ (Org.). Culturas políticas na história: Novos estudos. Belo Horizonte: Argvmentvum, 2009. p.?

PRADO JÚNIOR, C. História econômica do Brasil. São Paulo: Brasiliense, 1972.

SLENES, R. W. A. Os múltiplos de porcos e diamantes: a economia escrava de Minas Gerais no século XIX. Estudos históricos - Instituto de pesquisas econômicas, São Paulo, v. 18, p.??, 1988.

SIMONSEN, R. História econômica do Brasil. 7. ed. São Paulo: editora Nacional/Brasília, 1977. 